\title{
KARAKTERISASI ADSORPSI BATUBARA MUDA TERMODIFIKASI HIDROGEN PEROKSIDA MENGGUNAKAN METODE KONTINYU TERHADAP METILEN BIRU
}

\author{
Galuh Yuliani $^{1 *}$, Ghea Gristannia Grandistin ${ }^{1}, \&$ Anggoro Tri Mursito ${ }^{2}$ \\ ${ }^{1}$ Program Studi Kimia-Jurusan Pendidikan Kimia \\ Fakultas Pendidikan Matematika dan Ilmu Pengetahuan, Universitas Pendidikan Indonesia \\ ${ }^{2}$ Pusat Penelitian Geoteknologi Lembaga Ilmu Pengetahuan Indonesia \\ *Alamat korespodensi : gyuliani@gmail.com
}

\begin{abstract}
Abstrak: Kapasitas adsorpsi batubara muda masih lebih rendah bila dibandingkan dengan adsorben lain terutama bila dibandingkan dengan karbon aktif. Pada penelitian ini telah diupayakan peningkatan kapasitas adsorpsi pada batubara muda melalui pengayaan kadar oksigen dipermukaannya. Batubara muda yang digunakan berasal dari daerah Kalimantan, Indonesia, memiliki nilai kalori 5015,41 cal/g, 53,67 \% karbon, 6,02 $\%$ hidrogen, 38,58 \% oksigen, 0,69\% nitrogen, dan 0,12\% sulfur. Uji adsorpsi dilakukan menggunakan metode kontinyu dengan larutan metilen biru sebagai larutan model. Konsentrasi metilen biru ditentukan menggunakan spektrofotometri UV-Vis pada panjang gelombang $664 \mathrm{~nm}$. Data hasil pengujian FTIR menunjukkan batubara muda hasil modifikasi adanya penambahan intensitas pada $1750 \mathrm{~cm}^{-1}$ yang menandakan penambahan gugus $\mathrm{C}=\mathrm{O}$. Dari hasil uji adsorpsi menunjukkan adanya peningkatan kapasitas adsorpsi pada batubara muda hasil modifikasi yaitu dari $48,59 \mathrm{mg} / \mathrm{g}$ menjadi $91,11 \mathrm{mg} / \mathrm{g}$. Dapat disimpulkan bahwa oksidasi menggunakan hidrogen peroksida telah berhasil meningkatkan kemampuan adsorpsi batubara muda.
\end{abstract}

Kata kunci : Adsorpsi, batubara muda, hidrogen peroksida, metilen biru, metode kontinyu.

\begin{abstract}
Adsorption capacity of lignite is lower than other adsorbents, especially activated carbon. This study has been attempted on the improvement of adsorption capacity of lignite through oxygen enrichment on the surface. Lignite utilized in this study was originated from Kalimantan, Indonesian, has a calorific value of $5015.41 \mathrm{cal} / \mathrm{g}, 53.67 \%$ carbon, $6.02 \%$ hydrogen, $38.58 \%$ oxygen, $0.69 \%$ nitrogen, and $0.12 \%$ sulfur. Adsorption test was performed using a continuous method with methylene blue solution as a model solution. The results indicated that the lignite surface area increased to 48,16 $\mathrm{m} 2 / \mathrm{g}$ after the modification. FTIR characterization results showed an increase in intensity at $1705 \mathrm{~cm}^{-1}$ for the modified lignite which signifies the increase of absorption of $C=O$ functional groups. The adsorption test results indicated an increase in the adsorption capacity of modified lignite, from $48.59 \mathrm{mg} / \mathrm{g}$ to $91.11 \mathrm{mg} / \mathrm{g}$. It can be concluded that the oxidation using hydrogen peroxide has been successful in enhancing the oxygen compound's concentrateon the lignite surface and in improving the adsorption ability of lignite.
\end{abstract}

Keyword: Adsorption, lignite, hydrogen peroxide, methylene blue, continous method.

\section{PENDAHULUAN}

Dalam proses adsorpsi, karbon aktif merupakan material adsorben paling populer dan banyak digunakan dalam pengolahan air limbah. Tetapi harga dan biaya regenerasi karbon aktif yang relatif besar membatasi aplikasinya dalam pengolahan air limbah. Beberapa kelemahan dari karbon aktif ini mendorong banyaknya penelitian mengenai pemanfaatan batubara muda sebagai material adsorben alternatif pengganti karbon aktif (Bansal \& Goyal, 2005).

Salah satu adsorben murah yang telah banyak diteliti adalah batubara muda (Yuliani et al., 2012; Mohan et al., 2002). Batubara muda dipilih karena batubara muda memiliki beberapa kemiripan karakteristik dengan karbon aktif, yaitu porositas tinggi dan sifat pertukaran kation alami (Havelcova, 2009; Butler et al., 2007; Butler et al., 2005). Beberapa material penjerap yang diperoleh dari batubara muda untuk penghilangan zat warna dan logam yang terkandung dalam larutan juga telah dilaporkan (Havelcova et al., 2009; Qi et al., 2011; Karaca et al., 2004).

Dari beberapa literatur, dilaporkan bahwa sisi aktif dari batubara muda adalah gugus karboksilat yang dapat mengalami reaksi pertukaran kation dengan adsorbat (Yuliani et al., 2012; Qi et al., 2011). Oleh sebab itu, penelitian ini bertujuan untuk meningkatkan kadar karboksilat pada batu bara muda yaitu dengan cara mereaksikan dengan hidrogen peroksida.

Peningkatan kapasitas adsorpsi batubara muda melalui pengayaan kadar oksigen menggunakan hidrogen peroksida telah dilakukan melalui metode batch test dengan cara pengadukan menggunakan beberapa variabel waktu dan massa adsorben (Yuliani et al., 2014). Oksidasi menggunakan $\mathrm{H}_{2} \mathrm{O}_{2}$ dapat meningkatkan kadar oksigen dan kapasitas adsorpsi pada batubara muda. Kapasitas maksimum 
pada batubara muda meningkat setelah di modifikasi dari 51,81 mg/g menjadi sebesar 103,09 mg/g. Hal ini memperlihatkan bahwa adanya peningkatan porositas pada permukaan batubara muda hasil modifikasi (Yuliani et al., 2014).

Pada penelitian ini, dilakukan karakterisasi dan uji adsorpsi batubara muda asal Kalimantan termodifikasi hidrogen peroksida terhadap metilen biru menggunakan metode kontinyu.

\section{METODE}

\section{Preparasi Larutan Metilen Biru}

Larutan limbah model yang digunakan adalah larutan metilen biru. Larutan induk disiapkan dengan konsentrasi $1000 \mathrm{ppm}$. Untuk menentukan panjang gelombang maksimum dan membuat kurva kalibrasi disiapkan deret larutan standar dengan konsentrasi $0.5,1,1.5$, 2, dan 2.5 ppm. Penentuan panjang gelombang maksimum dilakukan pada rentang panjang gelombang 400-700 $\mathrm{nm}$ (jarak rentang 1 $\mathrm{nm})$. Panjang gelombang maksimum metilen biru pada analisis ini berada pada $664 \mathrm{~nm}$.

\section{Preparasi Batubara Muda Termodifikasi Hidrogen Peroksida}

Preparasi batubara muda termodifikasi mengikuti metode yang dilaporkan penelitian sebelumnya (Yuliani et al., 2014). Larutan $\mathrm{H}_{2} \mathrm{O}_{2}$ dengan konsentrasi $30 \%$ diencerkan ke dalam dua konsentrasi yaitu sebesar 5\% dan 10\%. Seberat $10 \mathrm{~g}$ batubara muda ditimbang kemudian dimasukkan ke dalam gelas kimia berukuran $250 \mathrm{~mL}$. Lalu ke dalam gelas kimia ditambahkan larutan $\mathrm{H}_{2} \mathrm{O}_{2}$ yang telah disiapkan kemudian diaduk menggunakan magnetic stirrer tanpa proses pemanasan hanya diaduk saja hingga homogen. Proses pengadukan diakukan selama $\pm 1 / 2$ jam. Setelah proses pengadukan selesai campuran disaring menggunakan kertas saring Whatmann berukuran 42 dan diambil residunya lalu dikeringkan pada suhu ruang.

\section{Uji Kapasitas Adsorpsi Batubara Muda dan Batubara Hasil Modifikasi}

Batubara muda tanpa perlakuan dengan ukuran 125-250 $\mu \mathrm{m}$ ditimbang $5 \mathrm{~g}$. Untuk batubara hasil modifikasi digunakan ukuran 125-250 $\mu \mathrm{m}$ dengan massa seberat $5 \mathrm{~g}$. Kemudian batubara muda yang sudah ditimbang tersebut dimasukan ke dalam kolom dengan susunan dari atas ke bawah (kapas, batubara muda, kapas) (Gambar 1). Setelah itu, sebanyak 500 $\mathrm{mL}$ larutan metilen biru dialirkan. Effluent yang keluar kemudian ditampung ke dalam botol tampung setiap 15 menit sekali kemudian dianalisis menggunakan spektrofotometer UV-Vis pada panjang gelombang $664 \mathrm{~nm}$.

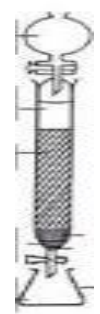

Gambar 1. Set Alat

\section{HASIL DAN PEMBAHASAN}

Hasil pengujian unsur-unsur yang terkandung pada batubara muda dan batubara muda termodifikasi hidrogen peroksida menunjukkan adanya perubahan yang ditunjukkan Tabel 1.

Tabel 1. Hasil analisis proksimat dan ultimat batubara muda dan batubara muda termodifikasi

\begin{tabular}{lll}
\hline Parameter & $\begin{array}{l}\text { Batubara } \\
\text { muda }\end{array}$ & $\begin{array}{l}\text { Batubara } \\
\text { muda } \\
\text { termodifikasi } \\
\mathbf{H}_{2} \mathbf{O}_{2} \mathbf{1 0} \%\end{array}$ \\
\hline Kalori (cal/g) & $5015,41 \mathrm{cal} / \mathrm{g}$ & $4657,24 \mathrm{cal} / \mathrm{g}$ \\
Air $(\%)$ & $37,21 \%$ & $18,02 \%$ \\
Abu $(\%)$ & $1,065 \%$ & $1,935 \%$ \\
Zat terbang $(\%)$ & $31,795 \%$ & $44,76 \%$ \\
Karbon & $29,935 \%$ & $35,385 \%$ \\
tertambat $(\%)$ & $53,67 \%$ & $47,39 \%$ \\
Karbon $(\%)$ & $6,02 \%$ & $6,33 \%$ \\
Hidrogen $(\%)$ & $38,58 \%$ & $41,010 \%$ \\
Oksigen $(\%)$ & $0,69 \%$ & 0,60 \\
Nitrogen $(\%)$ & $0,12 \%$ & $0,33 \%$ \\
Sulfur $(\%)$ & & \\
\hline
\end{tabular}

Dari hasil pengujian unsur pada batubara muda dan batubara muda modifikasi, terlihat adanya penurunan nilai kalori dan peningkatan kadar oksigen. Terjadinya penurunan nilai kalori disebabkan oleh melarutnya berbagai zat-zat mineral yang terkandung pada batubara muda saat proses oksidasi. Peningkatan kadar oksigen pada batubara muda modifikasi ini menunjukkan bahwa oksidasi batubara menggunakan hidrogen peroksida telah berlangsung.

\section{FTIR}

Batubara muda dan batubara muda termodifikasi diuji menggunakan FTIR untuk mengetahui perubahan gugus fungsi yang disebabkan oleh reaksi oksidasi menggunakan hidrogen peroksida.

Dari spektra FTIR batubara muda sebelum dan setelah modifikasi (Gambar 2), terdapat peningkatan intensitas pada serapan sekitar $1705 \mathrm{~cm}^{-1} \quad(-\mathrm{C}=\mathrm{O}$ karboksilat) diikuti dengan berkurangnya intensitas pada serapan sekitar $3000 \mathrm{~cm}^{-1}(\mathrm{C}-\mathrm{H})$. Selain peningkatan yang signifikan pada serapan gugus karboksilat, terdapat peningkatan pada serapan gugus $\mathrm{C}=\mathrm{C}$ walau tidak terlalu signifikan. Peningkatan ini menunjukkan terjadinya reaksi oksidasi yang menghasilkan gugus fungsi yang 
mengandung atom oksigen dan gugus fungsi yang mengandung ikatan rangkap.

Dari hasil spektra FTIR batubara muda modifikasi setelah adsorpsi menggunakan metilen biru (Gambar 3) terlihat adanya peningkatan intensitas pada serapan sekitar $1000-1600 \mathrm{~cm}^{-1}$ yaitu gugus C-O, C-N, dan C-H. Adanya puncak-puncak serapan untuk gugus-gugus tersebut menandakan adanya interaksi ikatan pertukaran molekul antara metilen biru dengan batubara muda modifikasi.

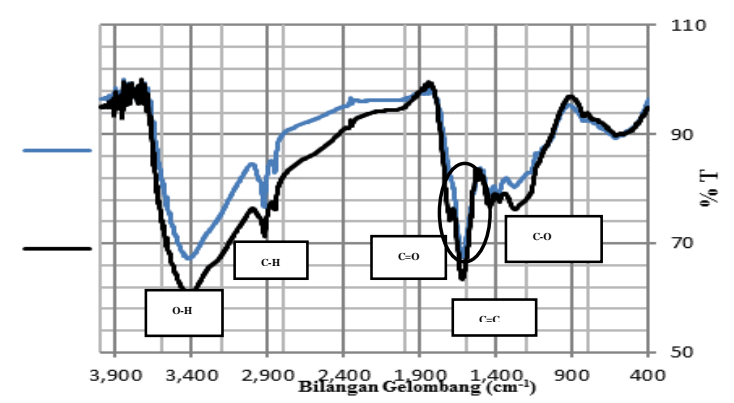

Gambar 2. Gabungan Spektra FTIR Batubara Muda (biru) dan Batubara Muda Modifikasi (hitam)

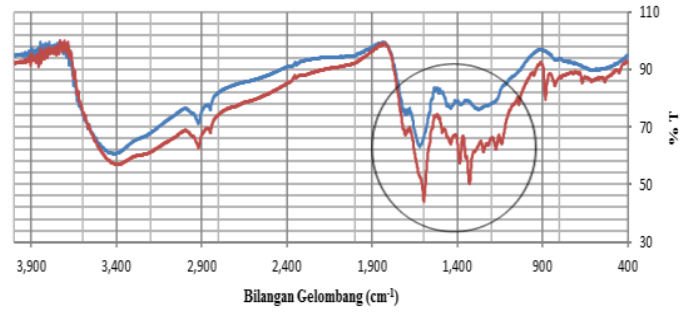

Gambar 3. Spektra FTIR Sebelum (biru) dan Sesudah (merah) Adsorpsi Batubara Muda Modifikasi

\section{Uji Kapasitas Adsorpsi Batubara Muda dan Batubara Muda Termodifikasi Hidrogen Peroksida}

Batubara muda termodifikasi memiliki kinerja yang lebih baik saat diaplikasikan sebagai filter bed adsorben menggunakan larutan model metilen biru. Berdasarkan data kapasitas adsorpsi kumulatif (q kumulatif), adsorben batubara muda termodifikasi (Gambar 4b) memiliki q kumulatif $60 \mathrm{mg} / \mathrm{g}$ (untuk modifikasi $5 \% \mathrm{H}_{2} \mathrm{O}_{2}$ ) dan $91 \mathrm{mg} / \mathrm{g}$ (untuk modifikasi $10 \% \mathrm{H}_{2} \mathrm{O}_{2}$ ).

Mekanisme adsorpsi pada permukaan batubara muda dapat terjadi secara fisik (melalui pori) maupun secara kimia (melalui mekanisme reaksi pertukaran kation) dalam proses adsorpsi batubara muda terhadap metilen biru yang merupakan zat warna yang kationik dengan gugus fungsi gugus $-\mathrm{NR}^{3+}$ atau $=\mathrm{NR}^{2+}$ dan ikatan $\mathrm{S}^{+}$. Mekanisme reaksi pertukaran kation yang terjadi telah dilaporkan pada literatur (Schafer, 1970).

$$
\begin{aligned}
& \mathrm{R}-\mathrm{COOH} \rightarrow \mathrm{R}_{-} \mathrm{COO}^{-}+\mathrm{H}^{+} \\
& \mathrm{R}-\mathrm{COOH}+\mathrm{Dye}^{+} \rightarrow \mathrm{R}-\mathrm{COO}-\mathrm{Dye}+\mathrm{H}^{+}
\end{aligned}
$$

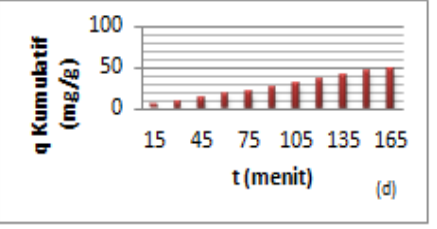

(a)

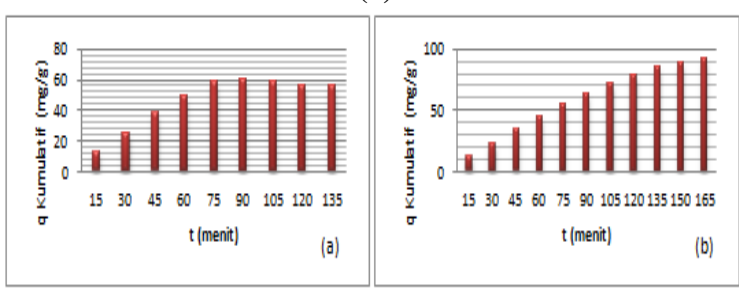

(b)

Gambar 4. (a) batubara muda, (b) batubara muda modifikasi $\mathrm{H} 2 \mathrm{O} 25 \%$ dan $10 \%$

\section{KESIMPULAN}

Oksidasi menggunakan hidrogen peroksida pada batubara muda dapat meningkatkan kadar oksigen dan meningkatkan kapasitas adsorpsi pada batubara muda yang diperlihatkan pada hasil analisis ultimat nilai kadar oksigen meningkat dari 38,58 \% menjadi $41,01 \%$. Kapasitas maksimum pada batubara muda meningkat setelah dimodifikasi dari $48 \mathrm{mg} / \mathrm{g}$ menjadi $91 \mathrm{mg} / \mathrm{g}$.

\section{UCAPAN TERIMA KASIH}

Penulis mengucapkan terima kasih kepada Pusat Penelitian Geoteknologi LIPI Bandung dan Skema Hibah Bersaing dari Dirjen Dikti Nomor 3463/UN40/PL/2013.

\section{DAFTAR PUSTAKA}

Bansal, R.C. \& Goyal, M. (2005). Activated carbon and its surface structure, in R.C. Bansal, M. Goyal (eds.), Activated carbon adsorption, CRC Press, Boca Raton.

Butler, C.J., Green, A.M. \& Chaffee, A.L. (2007). Remediation of mechanical thermal expression product waters using raw Latrobe Valey brown coals as adsorbents, Fuel, 86(7-8), 1130-1138.

Butler, C.J., Green, A.M. \& Chaffee, A.L. (2005). The influence of water quality on the reuse of lignite-derived waters in The Latrobe Valley, Australia, Coal Preparation, 25, 47-66.

Havelcova, M., Mizera, J., Sýkorová, I. \& Pekar, M. (2009). Sorption of metal ions on lignite and the derived humic substances, Journal of Hazardous Materials, 161, 559-564.

Karaca, S., Gürses, A. \& Bayrak, R. (2004). Effect of some pre-treatments on the adsorption of methylene blue by Balkaya lignite. Energy Conversion and Management, 45(11-12), 16931704.

Mohan, S.V., Rao, N.C. \& Karthikeyan, J. (2002). Adsorptive removal of direct azo dye from aqueous phase onto coal based sorbents: a kinetic 
and mechanistic study, Journal of Hazardous Materials, 90(2), 189-204.

Qi, Y., Chaffee, A.L. \& Hoadley, A.M. (2011). Characterisation of lignite as an industrial adsorbent, Fuel, 90(4), 1567-1574.

Schafer, H.N.S. (1970). Carboxyl groups and ion exchange in low-rank coals, Fuel, 49(2), 197213.

Yuliani, G., Noviyana, I. \& Setiabudi, A. (2014). Enrichment of Indonesian Low Rank Coal's
Surface (SOCs) using hidrogen peroxides and its adsortive properties. Advanced Material Research, 869, 159.

Yuliani, G., Qi, Y., Hoadley, A.F.A.; Chaffee, A.L. \& Garnier, G. (2012). Lignite clean up of magnesium bisulphite pulp mill effluent as a proxy for aqueous discharge from lignocellulosic biorefinery, Biomass and Bioenergy, $36,411-418$. 